\title{
Carta de los Miembros de los Comités Organizador y Científico del XI Congreso de Atención Primaria de Castilla-La Mancha
}

\begin{abstract}
Sr. Editor:
A propósito de los comentarios publicados en el último número de la revista (cartas al editor) por nuestro compañero Francisco Escobar, relativos al último Congreso Regional de Atención Primaria celebrado en Toledo, los abajo firmantes, miembros del comité organizador y científico del mismo, quisiéramos hacer una serie de consideraciones.
\end{abstract}

En primer lugar, queremos agradecer su sinceridad y esperamos que sus opiniones no hayan sido hechas desde el resentimiento, como refiere al final de su carta, sino desde su reconocido espíritu analítico e investigador. La crítica constructiva (habitualmente meditada, cortés y prudente) es siempre positiva, ya que sin ella no sería posible avanzar y mejorar.

La organización de un congreso médico es una tarea ardua y complicada, en la que es fácil cometer errores y difícil satisfacer las expectativas de todos los asistentes, y desde el primer día actuamos buscando el mejor resultado posible para todos.

Coincidimos plenamente con el autor de la carta en que el fomento y difusión de la investigación es el objetivo básico de nuestros congresos (y ello queda reflejado en la presentación en el de Toledo de 51 trabajos, entre comunicaciones orales y en formato póster). Pero ello no debe hacer que se descuide la faceta formativa que sin duda debe incluir todo congreso; las ponencias, los talleres y la presentación de casos clínicos son los formatos adecuados para cumplir con este fin. No creemos que ambos objetivos sean incompatibles, la búsqueda de un equilibrio entre los mismos puede ser clave para el éxito científico de un congreso.

También compartimos la preocupación por la cada vez más complicada financiación de los congresos; la reducción de gastos y la búsqueda de financiaciones alternativas creemos deberán ser fundamentales para garantizar ediciones futuras. Respecto a la reducción de gastos, a nadie se le escapa que puede centrarse en aspectos de restauración (cena de gala, cafés, etc.), pudiéndose complementar con otros aspectos que no pongan en peligro la calidad de los contenidos, como por ejemplo la sustitución del libro de ponencias por un disquete o un pendrive. Pero siendo realistas, actualmente la finan- ciación de un congreso depende en gran medida de la colaboración de la industria farmacéutica; la búsqueda de nuevas fuentes de financiación puede hacer disminuir esta dependencia y es un reto para futuros comités organizadores.

Igualmente coincidimos en la necesidad de reflexionar sobre el papel de la industria farmacéutica en nuestros congresos. En este sentido, tanto el comité organizador como el científico del congreso de Toledo mantuvieron en todo momento la independencia en la elección de las ponencias (y ponentes) $y$ de los talleres propios del congreso, que fueron decididas por ambos comités y ratificadas en las juntas directivas de ambas sociedades. Además, aquellas actividades organizadas por los laboratorios (symposiums y algún taller precongresual) fueron diferenciadas e identificadas claramente como tales con el objetivo de que todos los asistentes tuvieran conocimiento de esta circunstancia. Sin duda la existencia de actividades paralelas a las propias del congreso es una situación discutible y opinable, y como actividades complementarias las Sociedades Científicas implicadas deberán tomar decisiones, sopesando los pros y los contras en este sentido y trasladarlas a futuros comités.

Respecto al "sesgo biologicista" de las ponencias que se señala en la carta, creemos que responde a la realidad actual de nuestra especialidad y estamos de acuerdo en que debe ser objeto de una discusión mucho más sosegada y profunda de lo que sería posible en esta carta de réplica.

De la misma manera, coincidimos en la importancia de los comités científicos y en la trascendencia de la selección de sus integrantes, pero no creemos que el sistema de cuotas por sociedades y provincias sea negativo, como considera nuestro compañero, ya que garantiza la representatividad y favorece la independencia del comité a la hora de hacer las evaluaciones de los trabajos presentados, al permitir prescindir de la valoración del vocal de la provincia en cuestión, muchas veces implicado en las comunicaciones presentadas.

Sabemos de la importancia que tiene para la labor del comité científico el trabajar con criterios claros y objetivos. Baste decir que los criterios de valoración de los trabajos fueron, además de la calidad 
metodológica, el interés y relevancia del tema estudiado, la novedad u originalidad y la adecuación al congreso. Ello puede explicar que trabajos "metodológicamente pulcros" no hayan sido finalmente seleccionados para el congreso. En cualquier caso, rechazamos de plano la posibilidad de que, de haber cometido algún error en la valoración, éste haya sido con algún tipo de intencionalidad.

Aunque creemos que las cartas al editor de una revista no es el foro más oportuno para discutir la adecuación de la aceptación o rechazo de trabajos de investigación concretos, esperamos que este intercambio de opiniones, sin duda abierto a más ideas, redunde en la mejora de futuras ediciones. Sin duda nuestros compañeros de Cuenca y Albacete, próximas citas congresuales de nuestras sociedades, agradecerán todas las aportaciones que puedan ayudarles en su tarea.
Natalia Vallés Fernandez, José Manuel Comas Samper, Ramón Orueta Sánchez, Luis Fernando Álvarez Cueli, Javier Rodríguez Alcalá,

Ma José Lougedo Calderón, Gemma Alejandre Lázaro, Laura Rivilla Marugán, Alberto Berrocoso Martínez., Gustavo Rodríguez Roca, Francisco Gabriel Sánchez Nava Presidenta, Vicepresidente y Miembros del Comité Organizador del XI Congreso de Atención Primaria de Castilla-La Mancha

F. Javier Alonso Moreno, Francisco López de Castro, Javier Sánchez Olgado, Olga Fernández Rodríguez, Pilar Sorrius Sitges, Jorge Lema Bartolomé, Francisca Molina Escribano, Roberto Ramírez Parenteau, Dolores Retuerta

García, César Lozano Suárez, Enrique González Hidalgo, Antonio Segura Fragoso.

Presidente, Vicepresidente y Miembros del Comité Científico del XI Congreso de Atención Primaria de Castilla-La Mancha 